American Journal of Applied Sciences 4 (12): 1075-1078, 2007

ISSN 1546-9239

(C) 2007 Science Publications

\title{
Lightning Over-Voltages on Amman-Aqaba 400 KV Line
}

\author{
${ }^{1}$ Ghassan Halasa, ${ }^{2}$ Ibrahim Badran and ${ }^{1}$ Hafez El-Zayyat \\ ${ }^{1}$ Electrical Engineering Department, University of Jordan, Jordan \\ ${ }^{2}$ Electrical Engineering Department, Philadelphia University, Jordan
}

\begin{abstract}
An attempt is made to evaluate the lightning over-voltage failure rate for Amman- Aqaba $400 \mathrm{kV}$ transmission line by studying the geographical and temporal characteristics of lightning causing the line forced outages. The line was divided into three sections based on weather and pollution conditions. It was found that the line failure rate due to lightning over-voltages is low compared to other types of line outages. The investigation shows that the pollution conditions do cause line failures more than that due to lightning or adverse weather conditions. However, it is recommended that full investigation of the pollution nature including the effects of dust storms, maximum and minimum temperatures, wind speed and rain falls should be exercised for less line outages.
\end{abstract}

Key words: Lightning over-voltage, failure rate, insulation levels, creepage distance, shielding angle

\section{INTRODUCTION}

Over-voltages caused by lightning and pollution are the major adverse weather conditions that cause frequent transmission line outages. The characteristics of lightning and relationship between lightning and transmission line outages is still not fully understood by utility planners.

This paper deals with a study to estimate the Amman-Aqaba $400 \mathrm{kV}$ transmission line failure rates due to lightning strokes. A computer program was designed based on the procedure outlined in references ${ }^{[1,2]}$ to solve this problem. The $320 \mathrm{Km}$. line is divided into three different regions: the Aqaba, desert and mountainous regions.

The calculations are implemented on the middle and lower phases of the double circuit three phase lines for all three regions. The reason for excluding the upper phases from the calculations is that shielding angle is lowest at the upper phases and the failure rate will be definitely lower than the other phases. Furthermore, the line in question is a double circuit, the lower phase insulators have greater voltage across them than the top phase insulators because the coefficient of coupling is less for the lower insulators. Therefore, in this work, calculations are obtained for the middle and lower phases only.

The results are fully discussed and analyzed. The result of the line lightning performance is found to be satisfactory and highest for the desert region while lowest for the Aqaba region. The flow chart used in these calculations is shown at the end of this paper.
Amman/Aqaba $400 \mathrm{kV}$ transmission line: This line is the main line that links the Aqaba Thermal Power Station in the far south of the country, located on the shores of Aqaba Gulf, with Al-Husein Thermal Power Station near Amman, $320 \mathrm{Km}$ apart. The Aqaba area is connected with Marine line that runs under the Red Sea with Egypt. The northern part of the country is also connected with $230 \mathrm{kV}$ link with Syria. These interconnected lines form the Jordan National Grid.

In this work we are concerned with the $400 \mathrm{kV}$ transmission line between Aqaba Thermal Power Station and Amman South Substation of 320Km long, see Fig. 1. The line was constructed as double circuit and initially was operating at $132 \mathrm{kV}$. Recently, the line was increased to $400 \mathrm{kV}$. The line is with $2 \times 600 \mathrm{~mm}^{2}$ nominal cross sectional area aluminum alloy conductors per phase and with two No.7 AWG aluminum clad steel overhead earth wires. Suspension insulator strings are constructed as single vertical strings. Tension insulators are twin strings type ${ }^{[3]}$.

On the bare conductors the most onerous loading is due to maximum wind with velocity $36 \mathrm{~m} / \mathrm{s}$. In ice loaded areas, allowance is made for the appropriate sag values. The following are the line spans:

* The basic span $=410 \mathrm{~m}$.

* Wind span $=1.1 \times 410=451 \mathrm{~m}$

* $\quad$ Maximum weight $\mathrm{span}=2$ xbasic $\mathrm{span}=820 \mathrm{~m}$ for suspension towers and 3 xbasic span $=1230 \mathrm{~m}$ for tension towers.

Corresponding Author: Ibrahim Badran, Electrical Eng. Department, Philadelphia University, P O Box 1, Jordan, 19392 
Am. J. Applied Sci.4 (12): 1075-1078, 2007

* Minimum weight span $=30 \%$ of sum of adjacent spans

* Maximum actual span does not exceed 1.5 equivalent span

* Minimum actual span will not be less than 0.4 of equivalent span

* Maximum ratio of adjacent spans does not exceed $1-2.5$

The following temperatures are recommended for the design of the line:

* Minimum Temperature $-5^{\circ} \mathrm{C}$

* Every day Temperature $26^{\circ} \mathrm{C}$

* Maximum Temperature $75^{\circ} \mathrm{C}$

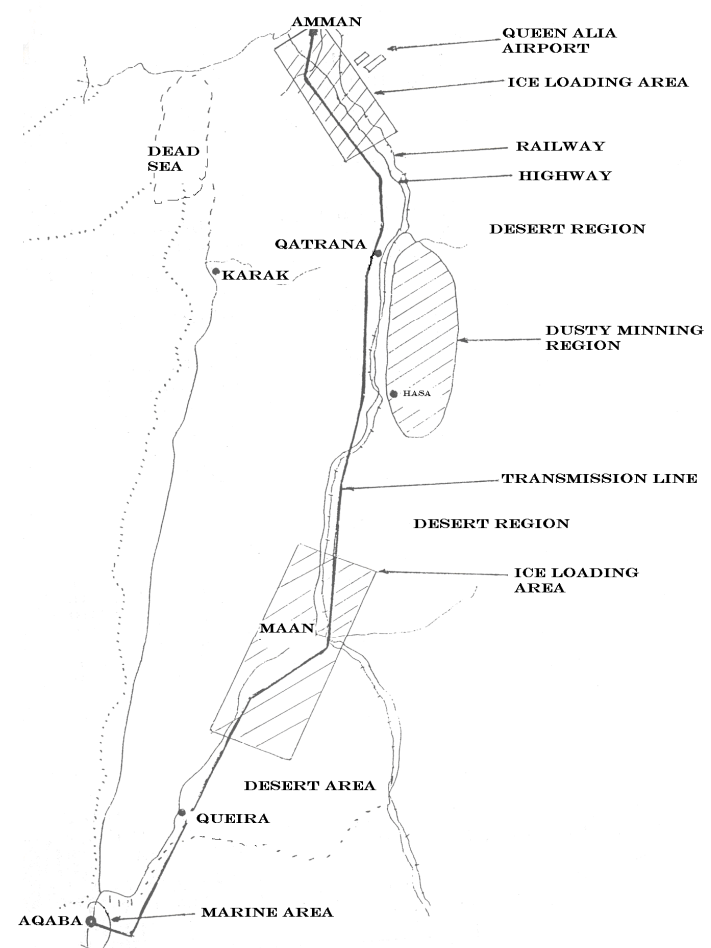

Fig. 1: Weather and pollution map and $400 \mathrm{KV}$ line path

* The insulation levels (withstand voltage) are: $1050 \mathrm{kV}$ switching surge voltages, $1425 \mathrm{kV}$ lightning impulses, $460 \mathrm{kV}$ power frequency voltage.

* As for insulators types, cap and pin open profile insulators are used for desert areas. Antifog units are used for the marine areas. Insulators are of toughened glass type. Insulator strings are vertical single strings for suspension towers and duplex strings for tension towers.
The following are creepage distances

* Desert Areas 32mm / kV

* Desert Area with high pollution $38 \mathrm{~mm} / \mathrm{kV}$

* Marine Areas $38 \mathrm{~mm} / \mathrm{kV}$

The following are the clearances:

* $\quad$ Switching Surge Clearance $3.8 \mathrm{~m}$

* Power Frequency Clearance $1.0 \mathrm{~m}$ at $60^{\circ} / 2.42 \mathrm{~m}$ at $40^{\circ}$ insulator swing

* Impulse Clearance $3.11 \mathrm{~m}$

* The clearance between the twin- bundled conductors is $500 \mathrm{~mm}$.

Table 1: Tower Data

\begin{tabular}{lcc}
\hline & Middle phase & Lower phase \\
\hline Operating voltage $(\mathrm{kV})$ & 400 & 400 \\
Tower Class & 3 & 3 \\
Tower Height $(\mathrm{m})$ & 52.05 & 52.05 \\
Smallest Tower Width $(\mathrm{m})$ & 3.0 & 3.0 \\
Phase Conductor Diameter $(\mathrm{cm})$ & 3.15 & 3.15 \\
Shield Wire Diameter $(\mathrm{cm})$ & 1.13 & 1.13 \\
Conductors Bundles Per Phase & 2 & 2 \\
Bundle Spacing (m) & 0.50 & 0.50 \\
Number of Shield Wires & 2 & 2 \\
Span (m) & 410 & 410 \\
Minimum Clearance (m) & 21.14 & 10.64 \\
Conductor Height at Tower $(\mathrm{m})$ & 33.29 & 22.79 \\
Phase Spacing (m) & 12.0 & 12.0 \\
Ground Wire Separation $(\mathrm{m})$ & 12.0 & 12.0 \\
Shield Angle & $15.78^{\circ}$ & $5.66^{\circ}$ \\
Insulation String Length $(\mathrm{m})$ & 5.76 & 5.76 \\
Footing Resistance $(\Omega)$ & 10 & 10 \\
\hline
\end{tabular}

The towers used are as follows:

* 4DL Suspension Tower

* 4D1 Section or $10^{\circ}$ angle tower

* 4D2 Angle from 10-20

* 4D3 Angle from 20-30

* 4D6 Angle from 30-60

* 4D9 Angle from 60-90

* 4DT Terminal tower

* 4SG Flat Formation Single Circuit Gantry Structures

* 4TR Transposition

The tower considered in the calculations in this work is the suspension tower type (4DL), shown in Fig. 2.

The tower dimensions are given in Table 1. The types of foundations are considered as soft soil, $50 \%$ soft rock, $100 \%$ soft rock, hard rock. For simplicity, the footing resistance used in this work is $10 \mathrm{ohms}$.

The following factors of safety are considered:

\begin{tabular}{ll}
\hline Condition & Safety factor \\
\hline Maximum Applied Transverse Loads & 1.7 \\
Vertical loads & 2.0 \\
Broken Wire Conditions & 1.25 \\
\hline
\end{tabular}


Table 2: Flashover rates

\begin{tabular}{|c|c|c|}
\hline \multicolumn{3}{|l|}{ phase } \\
\hline Flashover Voltage of Insulators at $6 \mu \mathrm{s}(\mathrm{kV})$ & 3428.36 & 3428.36 \\
\hline \multicolumn{3}{|l|}{ Mean Height of Phase Conductor } \\
\hline Most Exposed to Lightning (m) & 25.19 & 14.69 \\
\hline Conductor Corona Radius (m) & 0.494 & 0.583 \\
\hline Corona Radius of Bundle (m) & 0.583 & 0.672 \\
\hline Self Surge Impedance of Phase Conductor (ohms) & 319.064 & 280.92 \\
\hline \multicolumn{3}{|l|}{ Minimum Stroke Current Causing } \\
\hline Shielding Failure (kA) & 21.49 & 24.41 \\
\hline \multicolumn{3}{|l|}{ Distance Between Shield Wire and } \\
\hline Outer Phase for Effective Shielding (m) & 6.6109 & 14.41 \\
\hline Shield Angle & $19.412^{\circ}$ & $26.22^{\circ}$ \\
\hline Insulator's Flashover Voltage at $2 \mu \mathrm{s}(\mathrm{kV})$ & 4793.291 & 4793.291 \\
\hline Insulator's Flashover Voltage at $6 \mu \mathrm{s}(\mathrm{kV})$ & 3428.36 & 3428.36 \\
\hline Estimated Tower Top Voltage (kV) & 8627.92 & 8627.92 \\
\hline Shield Wire Corona Radius (m) & 1.316 & 1.316 \\
\hline Self Surge Impedance of Each Shield Wire (ohms) & 393.113 & 393.113 \\
\hline Combined Surge Impedance of Both Shield Wires & 261.568 & 261.568 \\
\hline Coupling Factor for Each Phase Conductor & 0.307 & 0.198 \\
\hline Tower Surge Impedance (ohms) & 215.188 & 215.188 \\
\hline Tower Travel Time $(\mu \mathrm{s})$ & 0.174 & 0.174 \\
\hline Span Travel Time ( $\mu \mathrm{s})$ & 1.519 & 1.519 \\
\hline \multicolumn{3}{|l|}{ Travel Time from Tower Top to } \\
\hline Each Cross-arm $(\mu \mathrm{s})$ & 0.043 & 0.078 \\
\hline Intrinsic Circuit Impedance (ohms) & 81.345 & 81.345 \\
\hline Tower Wave Impedance (ohms) & 56.038 & 56.038 \\
\hline Tower Damping Factor & 0.244 & 0.244 \\
\hline Footing Resistance Refraction Factor & 0.089 & 0.089 \\
\hline Per Unit Tower Top Voltage at $2 \mu \mathrm{s}$ & 24.234 & 24.234 \\
\hline \multicolumn{3}{|l|}{ Reflected Voltage Component from } \\
\hline Adjacent Towers at $2 \mu \mathrm{s}$ & 0.00 & 0.00 \\
\hline Cross-arm Voltage For Each Phase (pu) & 20.435 & 17.366 \\
\hline Insulator Voltage for Each Phase (pu) & 12.988 & 12.561 \\
\hline Per Unit Tower Top Voltage at $6 \mu \mathrm{s}$ & 9.29 & 9.29 \\
\hline \multicolumn{3}{|l|}{ Reflected Voltage Component From } \\
\hline Adjacent Towers at $6 \mu \mathrm{s}$ & -1.042 & -1.042 \\
\hline Insulators' Voltage for Each Phase (pu) at $6 \mu \mathrm{s}$ & 5.713 & 6.613 \\
\hline
\end{tabular}

Transmission line sectioning: For the purpose of this study, the transmission line path was divided into three main regions. Since the transmission line originates at Aqaba city, situated on the shores of Aqaba Gulf (Red Sea), this region is considered as marine region.

The length of this region is $60 \mathrm{~km}$. The major area that the line passes through is the desert area. There is a small area with dust from mines in the Hasa area; since the line passes west of this area and the prevailing wind is westerly, this area was considered as desert region. The transmission line length in the desert region is $220 \mathrm{~km}$. There are two mountainous areas in the north and the south of the country the transmission line passes through. These areas are considered as 'ice loading' areas. The total length of the line in this area is $40 \mathrm{~km}$. The three major areas are shown on the map of
Fig. 1: The keraunic level was estimated as 13 for the marine region, 19 for the desert region and 15 for the mountainous region.

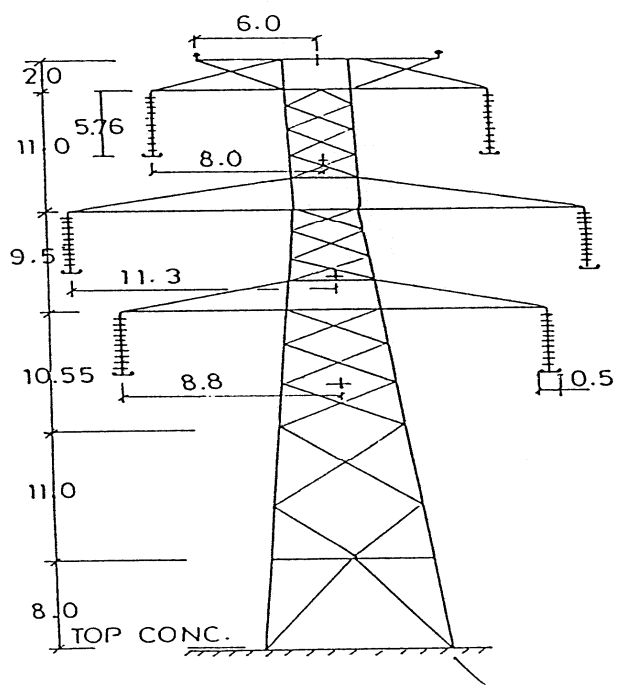

Fig. 2: The tower under study (dimensions in meters)

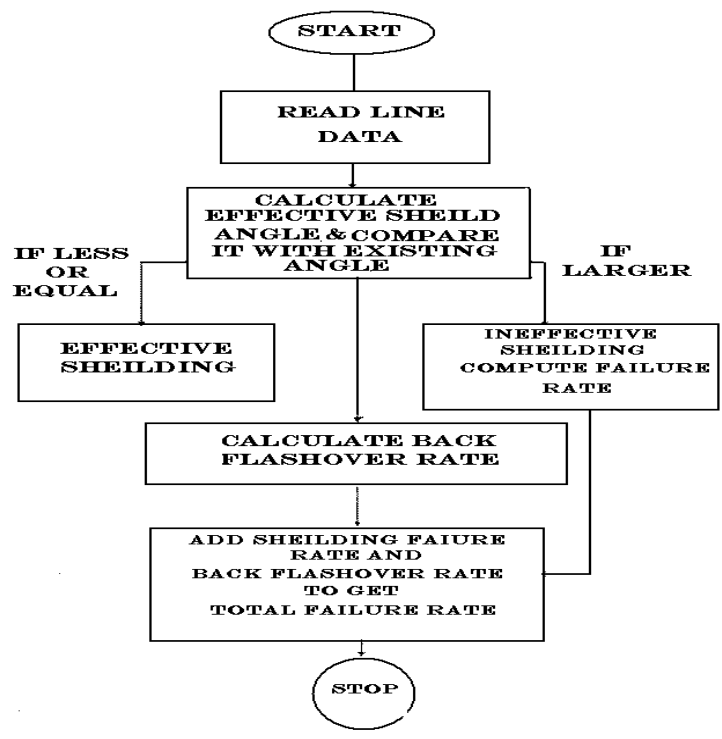

Fig. 3: Line failure rate calculations flowchart

\begin{tabular}{llll} 
Table 3: & Values of total strokes & & \\
\hline & Mountain & Desert & Marine \\
\hline Strokes Incident to Earth $/ \mathrm{km}^{2} /$ year & 1.8 & 2.28 & 1.56 \\
Total Flashes to Line $/ 100 \mathrm{~km} /$ year & 46.64 & 59.0764 & 40.4207 \\
\hline
\end{tabular}

Calculations of line failure rate: The data used in the calculations of flashover rates are shown in Table 2 and 3. The values of total strokes are shown in Table 3 . 
Am. J. Applied Sci.4 (12): 1075-1078, 2007

Table 4: Lightning performance results

\begin{tabular}{|c|c|c|c|c|c|c|}
\hline \multirow{2}{*}{$\begin{array}{l}\text { Region } \\
\text { Phase }\end{array}$} & \multicolumn{2}{|l|}{ Mountain } & \multicolumn{2}{|l|}{ Desert } & \multicolumn{2}{|l|}{ Marine } \\
\hline & Middle & Lower & Middle & Lower & Middle & Lower \\
\hline $\begin{array}{l}\text { Effective Tower Flashes/ } 100 \mathrm{~km} / \mathrm{year} \\
\text { Expected Number of Strokes Causing }\end{array}$ & 27.984 & 27.984 & 35.446 & 35.446 & 24.252 & 24.252 \\
\hline Flashovers Per Phase & 0.021 & 0.019 & 0.027 & 0.024 & 0.018 & 0.017 \\
\hline Total Back-Flashovers $/ 100 \mathrm{~km} /$ Year & 0.050 & 0.046 & 0.064 & 0.058 & 0.044 & 0.040 \\
\hline Total Failures/10km/Year & 0.050 & 0.046 & 0.064 & 0.058 & 0.044 & 0.040 \\
\hline Expected Number of Outages Per Year & 0.0201278 & 0.0184551 & 0.137037 & 0.125649 & 0.021661 & 0.023992 \\
\hline Total Over voltages Expected Per Year & 0.210950 & 0.0683885 & 1.43622 & 0.465612 & 0.274235 & 0.088905 \\
\hline
\end{tabular}

The calculation procedures used are the same as those outlined in references 2 and 4 . A computer program was written for this purpose. The flow chart of this program is shown in Fig 3. The calculations are implemented by calculating the back-flashover rate and then the shielding angle is calculated. If the actual shielding angle is equal or more than the calculated angle, this means that the shield wires protect the line and no failure occurs. If the actual shielding angle is less than the calculated angle, then the result is a line failure.

In this case the back-flashover rate is added to the shielding failure rate to obtain the transmission line total failure rate. The numerical failure rates of the line in question are tabulated in Table 4 for all three regions.

\section{DISCUSSION}

From the results obtained in Tables 2 and 3, it is clear that the calculations were made only for middle and lower phases of the double circuit three-phase lines for the three selected geographical regions. More accurate results can be obtained if the upper phase is included. However, the results obtained are considered as approximate solution for the system under investigation.

Moreover, some accurate results can be obtained using stochastic solutions such as Markov technique by considering normal and adverse weather conditions including pollution due to dust storms, humidity and temperature variations as well as thunder storms occurrences. These combined factors are severely affecting the transmission lines failure rate estimations and may be left for future study ${ }^{[4-7]}$.

\section{CONCLUSIONS}

The following points are concluded:

* The study shows that the transmission line failure rate due to lightning strokes is low compared to other types of line outages.
* The effective number of flashes due to middle phases shows the desert region suffers the highest rate as compared to Aqaba and mountain regions.

* The total failures per $100 \mathrm{~km} / \mathrm{year}$ is also found to be the highest for the desert region.

* The expected number of outages and the total overvoltages expected per year are found to be also the highest for the desert region.

* The total over voltages expected per year for the middle phases for all areas are much higher than that for lower phases. While the all other rates are close for both the middle and lower phases.

\section{REFRENCES}

1. Transmission Line Reference Book $345 \mathrm{kV}$ and Above, 1985. Electric Power Research Institute. 2nd Edn., Palo Alto, California, USA.

2. IEEE Working Group Report, 1993. Estimating Lightning Performance of Transmission Lines II, Updates to Analytical Model. IEEE Trans. on Power Delivery, 8: 1254-1267.

3. Jordan Electricity Authority, 1978. Climatic Data. Department of Specifications, Standards and Regulations, Amman, Jordan.

4. Anderson, J.G., 1961. Monte carlo calculation of transmission line lightning performance. AIEE Trans. (Power Apparatus and Systems), 80: 414420.

5. Meliopoulos, A.P.S. and R. Cooper, 2000. Transmission line lightning performance based design. IEEE Power Engineering Society Winter Meeting, 4: 2898-2903.

6. Wakai, T. et al., 2004. A topographical factor analysis of lightning strokes to transmission lines and estimation of lightning strokes frequency to transmission lines. J. Electrostat., 60: 211-222.

7. Sato, A., 1980. estimating transmission-line lightning outages by stochastic calculation. IEEE Trans. on Power Apparatus and Systems, 99: 10791088. 